\title{
Validating of Knowledge, Attitudes, and Practices Questionnaire for Prevention of COVID-19 infections among Undergraduate Students: A RASCH and Factor Analysis
}

\author{
Muhammad Saefi ${ }^{1}$, Ahmad Fauzi ${ }^{2 *}$, Evi Kristiana ${ }^{3}$, Widi Cahya Adi ${ }^{4}$, M Muchson ${ }^{1}$, M Eval Setiawan ${ }^{5}$, \\ Novita Nurul Islami ${ }^{6}$, Dian Eka Aprilia Fitria Ningrum ${ }^{7}$, M Alifudin Ikhsan ${ }^{1}$, Mavindra Ramadhani ${ }^{8}$

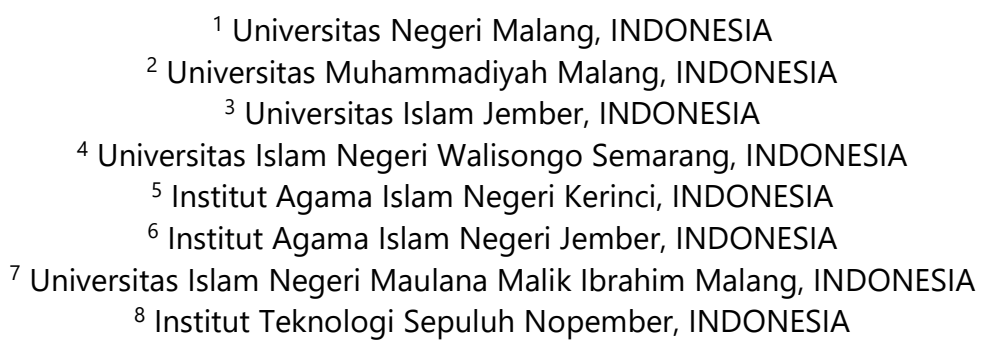

Received 2 June 2020 - Accepted 8 September 2020

\begin{abstract}
Students' poor understanding of COVID-19 can contribute to an increase in the number of COVID19 cases.. However, there is no validated instrument for measuring undergraduate student knowledge about COVID-19. This study is at the cutting edge of validating the psychometry of students' knowledge, attitudes, and practices (KAP) toward COVID-19. The assessment instrument consists of 18 items in the knowledge domain, 6 items in the attitude domain, and 12 items in the practice domain. This questionnaire underwent expert validation prior to being administered to 389 respondents. A RASCH model and Confirmatory Factor Analysis (CFA) were applied to evaluate the psychometric characteristics of the instrument. A four-factor model was tested for measurement model validity for knowledge domain, and two-factor model for attitude and practice domains by CFA. The results showed model yielded adequate goodness-of-fit values. In addition, results of RASCH model showed that the item content validity index was high. The item reliability for all the three domains was good, with a high separation index value. Thirty-six items were fitted to the model, based on recommended mean-square fit values, standardized Z-scores, and point-measure correlation coefficients. The response set in the questionnaire fit the Andrich threshold estimates well, and functioned as an appropriate model for the response category. The questionnaire thus shows excellent psychometric characteristics. Thus, this instrument can be used to measure undergraduate student KAP and can be implemented in future studies that want to assess the effectiveness of interventions to improve students' understanding of COVID-19.
\end{abstract}

Keywords: COVID-19, KAP survey, knowledge, attitudes, practices, science education

\section{INTRODUCTION}

The present outbreak of coronavirus disease 2019 (COVID-19) is a serious global natural phenomenon and citizens worldwide are expected to act and behave appropriately. Everyone must be prepared for any eventuality in their respective locations (Kain \& Fowler, 2019; Saravara, 2007). Individuals are expected to minimize the transmission rate and avoid actions that could endanger their own health, or that of the 


\section{Contribution to the literature}

- Many Indonesian students appear to have a poor understanding of COVID-19, trusting conspiracy theories and hoax news more than scientific findings.

- Some studies exploring knowledge levels and KAP toward COVID-19 worldwide have been carried out by several research teams, but their instruments have not been properly validated, especially in the Indonesian students cohort.

- The instrument validated in this study can be used either as a basic reference tool to measure the level of student's KAP toward prevention of COVID-19 and assessing the efficacy of education interventions, or employed as the main instrument for future work.

community (Annas et al., 2008; Malm et al., 2008). All elements of society are expected to help their governments in overcoming the outbreak, a perhaps unimaginable situation in the past, through public awareness and preventive behavior (Barennes et al., 2010; Takahashi et al., 2017). Unfortunately, low levels of knowledge and scientific literacy and limited application of scientific attitudes, among academics and nonacademics alike, have implications for the increasingly complex handling of this pandemic (Ashrafi-Rizi \& Kazempour, 2020; Fauzi et al., 2020; Uscinski et al., 2020). Moreover, the majority of students in Indonesia obtained information related to COVID-19 from social media (Fauzi et al., 2020). Social media is classified as a source of information that contains much unreliable information (fake news / hoax) and plays a role in spreading various conspiracy theories about COVID-19. (Easton, 2020).

During the COVID-19 pandemic, the science education sector has played an important role in collaboration with the health sector and other supporting fields (Bakhtiar, 2016; Barennes et al., 2010; Karlsen et al., 2015). Science education not only contributes to one's knowledge, but it also affects a person's general attitudes and practices toward infectious disease. Education may thus contribute effectively to controlling the pandemic (Albright \& Allen, 2018; Jones-Konneh et al., 2017), with students being expected to implement behaviors according to the education they have received. One of the most important groups for the purpose of tackling the pandemic is college students. College students are expected to not only help inform the surrounding community about the COVID-19 pandemic, but also to be the role models of attitudes and practices in dealing with it. In this way, science education can have a greater and longer impact on disease management compared to technological interventions (Kouadio et al., 2012; Taylor et al., 2015).

On the other hand, the health of college students is itself a major concern of countries around the world since they are at high risk of COVID-19 infection (Sahu, 2020; Wang et al., 2020). Students' high mobility is a main contributing factor to COVID-19 infection and transmission (Kraemer et al., 2020; Sirkeci \& Yüceşahin, 2020). In East Java, Indonesia, the COVID-19 rapid response team reported that its first case was a college student who had travelled to other red zones in the country as part of their program of study. Given the large number of positive cases of COVID-19 among students, research into student's knowledge, attitudes, and practices (KAP) toward COVID-19 needs to be fostered through a cross-sectional study.

COVID-19 does not exhibit a definitive set of symptoms, as some people are asymptomatic or showing no symptoms at all (Hu et al., 2020; Singhal, 2020). The WHO statement that COVID-19 may never go away implies a particular threat to students if they are expected to participate in face-to-face classroom activities. College students tend to have little physical activity, poor immunity, irregular routines, and poor nutrition, all of which exacerbate COVID-19 infections. To make matters worse high population density and close contact with fellow students both on and off campus create favorable conditions for COVID-19 transmission. Poor knowledge and attitudes may be an obstacle in seeking treatment, or reporting illness to university healthcare officials or the nearest health facility, thus contributing to a high prevalence of COVID-19 both in and around universities.

The most common approach to the assessment of KAP is via a questionnaire. KAP instruments are commonly used in the social sciences and in public health, and have been applied more recently in research related to the prevention of COVID-19 infection (Fauzi et al., 2020; Mohd Hanafiah \& Wan, 2020; Olapegba \& Ayandele, 2020; Rahman \& Sathi, 2020; Saefi et al., 2020; Wadood et al., 2020; Zhong et al., 2020). Previous questionnaires pertaining to COVID were not, however, developed in a systematic manner. To the best of our knowledge no specific research has been undertaken on developing KAP questionnaires relevant to COVID-19, especially for university students. New instruments must be validated in order to maintain a standardized approach and to ensure the quality of the student's KAP assessment. The existence of a validated KAP instrument allows various studies to measure the effectiveness of learning interventions or educational programs on students' KAP level changes. Based on examples of questionnaires used in previous KAP assessment studies, and using explanations and recommendations 
Table 1. The main domains and theories covered in the SKAPCOV-19 questionnaire

\begin{tabular}{lll}
\hline Domains & Factors & Definitions \\
\hline Knowledge & Etiology & Knowledge of the characteristics, causes, and symptoms of COVID-19. \\
\cline { 2 - 3 } & Risk group & $\begin{array}{l}\text { Knowledge about the difference in the level of danger of COVID-19 in certain } \\
\text { groups. }\end{array}$ \\
\cline { 2 - 3 } & Transmission of COVID-19 & Knowledge about how the spread or transmission of COVID-19 \\
\cline { 2 - 3 } & Preventions of COVID-19 & $\begin{array}{l}\text { Knowledge about actions that can be taken to prevent, reduce, eradicate, or } \\
\text { eliminate COVID-19. }\end{array}$ \\
\hline Attitude & Barriers to compliance & $\begin{array}{l}\text { Someone's noncompliance in preventing, reducing, eradicating, or eliminating } \\
\text { COVID-19. }\end{array}$ \\
\cline { 2 - 3 } & Self-motivation & $\begin{array}{l}\text { Desire or impulse within a person to prevent, reduce, eradicate, or eliminate } \\
\text { COVID-19. }\end{array}$ \\
\hline Practice & Prevention practices & $\begin{array}{l}\text { Several behaviours that are carried out to prevent, reduce, eradicate, or } \\
\text { eliminate COVID-19. }\end{array}$ \\
\cline { 2 - 3 } & Health lifestyle & $\begin{array}{l}\text { Lifestyle that is carried out by taking into account a number of health factors, } \\
\text { including food, rest patterns, exercise and clean living. }\end{array}$ \\
\end{tabular}

from the $\mathrm{WHO}$ and the Indonesian government with respect to stemming the spread of COVID-19, we developed the questionnaire on student KAP toward COVID-19 (SKAPCOV-19). Therefore, the main objective of this study was to investigate the dimensionality and measurement properties of the SKAPCOV-19 questionnaire, using a combination of both modern psychometrics analysis, i.e. CFA and RASCH models.

\section{METHODS}

The development of a questionnaire on student KAP toward the COVID-19 pandemic involved three main stages: (1) literature review and item generation, (2) face and content validity, and (3) assessment of construct validity and reliability using the CFA and RASCH models.

\section{Literature Review and Item Generation}

The initial step in developing the instrument was to identify the most representative variables. These were identified and selected based on a literature review of articles published in international journals and on websites of the government of the Republic of Indonesia regarding the prevention of the spread of COVID-19 (Fauzi et al., 2020; Gugus Tugas Percepatan Penanganan COVID-19, 2020; Mohd Hanafiah \& Wan, 2020; Olapegba \& Ayandele, 2020; Saefi et al., 2020; Zhong et al., 2020), SARS, and MERS-COV infection (Mohammed Dauda Goni et al., 2019, 2020). Based on these variables, a draft of the instrument of student KAP toward the COVID-19 pandemic (SKAPCOV-19) consisting of 36 questionnaire items was produced.

\section{Description of the Draft SKAPCOV-19 Questionnaire}

Part 1 ( $n=18)$ was developed to test the basic knowledge of students on the etiology, risk groups, transmission, and prevention of COVID-19. Student responses were assessed using pre-defined options of "no," "not sure," and "yes" (Burns et al., 2008). There were six negative statements (item numbers 6, 7, 8, 11, 12 , and 13) and the remaining 12 items were positive. In positive questions, students who choose the "yes" option will get a score of 1 , while the "no" and "not sure" answers will get a score of 0 , and vice versa.

Part $2(n=6)$ was developed to assess students' attitudes toward the COVID-19 pandemic. This includes the barriers to compliance and self-motivation. The approach used is a 3 -point Likert scale with scores of $1=$ disagree, 2 = not sure, and 3 = agree.

Part $3(n=12)$ was developed to evaluate student practice in suppressing the spread of COVID-19. This includes prevention efforts and a clean and healthy lifestyle. The approach used is a 3-point Likert scale with scores of 1 = never, 2 = occasionally, and 3 = always. The main domains and theories covered in the questionnaire are shown in Table 1.

\section{Face and Content Validity}

Face validity is used to evaluate whether an indicator appears to be a reasonable measure in terms of word order, structure, order, and assessment format (Creswell, 2012). Conversely, content validity is used to examine the relevance, clarity, simplicity, and completeness of the instrument (Rodrigues et al., 2017). Six senior lecturers in biology from several state universities in Indonesia were asked to review the initial draft of the instrument. Content validity was assessed quantitatively and qualitatively. The experts were asked to label each item as follows: 1, not useful or not essential; 2, useful but not essential; or 3, essential; they were also asked to provide comments and suggestions for improvement. Overall expert scores were then calculated and qualified by means of a content validity index (CVI), in which items with a CVI $>0.79$ would be retained, 0.70-0.79 revised, and $<0.70$ rejected (DeVon et al., 2007). 


\section{Assessment of Construct Validity and Reliability} using the RASCH Measurement Model

\section{Population and sample}

The population for this study consisted of students from 10 universities in Indonesia. The inclusion criteria were as follows: (1) undergraduate students, (2) nonmedical majors, (3) healthy without COVID-19, and (4) never suffered from COVID-19. Simple random sampling was used to obtain a diverse pool of respondents. The selection of the 10 universities was made using a random number table, while 389 students were selected from these universities using a systematic sampling technique. A sample size of 250-500 is sufficient for RASCH analysis and can produce good output for estimating item locations (Hagell \& Westergren, 2016; J. Linacre, 1994) and it was sufficient for CFA analysis according to the minimum benchmark sample for factor analysis (Dörnyei, 2003; Tabachnick \& Fidell, 2007).

\section{Data collection}

Data collection was performed using an online crosssectional survey (Creswell, 2012), since communitybased data collection was not possible. This was carried out for 1 week, from April 27 to May 3, 2020. Relying on a network of lecturers at various universities in Indonesia, the instrument in Google Forms was shared with lecturers and students via a WhatsApp group (WAG).

\section{Data analysis}

Confirmatory factor analysis (CFA): The questionnaire was adapted from several previous KAP questionnaires with known dimensions, i.e. from Saefi et al. (2020), Goni et al. (2020), and Mohammd Dauda Goni et al. (2020). Consequently in this study, the factorial structure of SKAPCOV-19 questionnaire was tested using CFA. We investigated the two hypothesized models, namely, the first order model, four-factors models for the knowledge domain, and two-factors models for the attitude and practice domains. Checking the adequacy of the model was measured based on absolute fit indices, namely the Chi-Square Goodness Test ( 2 / df), standardized root mean square residual (SRMR), the root mean square error of approximation (RMSEA), comparative fit index (CFI) , the goodness of fit index (GFI), and the adjusted goodness of fit index (AGFI) (McDonald \& Ho, 2002).

Rasch analysis: Before measuring item reliability and fit statistics, assumption tests for unidimensionality and local independence were conducted. The value of item reliability, separation indices, and fit statistics, including infit and outfit mean-square (MNSQs, infit/outfit), standardized Z values (ZSTDs, infit/outfit), and pointmeasure correlation coefficient (PTMEA Corr) were evaluated. The RASCH model analysis output for the data derived from the 36-item SKAPCOV-19 questionnaire was displayed and interpreted according to recommendations as follows: item reliability values $>$ 0.80 and separation index values $>2.0$ were classified as good; value ranges for infit and outfit MNSQ between 0.6 and 1.5; PTMEA Corr values from 0.3 to 0.7 ; and ZSTDs \pm 2.0 accepted as measures of item fitness (Bond $\&$ Fox, 2007). Items that met all these criteria, or had only one fit statistic value outside the specified ranges, were retained, while items with two or more misfit parameters were deleted (Ismail et al., 2020). The rating scales for factors associated with attitudes and practices were also analyzed to evaluate whether the choices were potentially confusing. Finally, the three domains were analyzed using a Wright Map to visualize the distribution of questions' level of difficulty, and using the test information function to determine the level of student ability that would be optimal for this instrument.

\section{RESULTS}

\section{Face and Content Validity}

None of the questionnaire items were found to suffer serious problems of structure and wording, though a number of improvements were made based on the comments and suggestions of experts in order to improve the face validity of the instrument. The results of the content validity test on the 36 questionnaire items showed that all items have a CVI $>0.80$ for all domains, with an average CVI of $0.97-0.99$. Thus, all 36 items on the draft SKAPCOV-19 questionnaire were considered essential for measuring student's KAP toward the COVID-19 pandemic.

\section{Confirmatory Factor Analysis}

Results of the CFA indicated that the four-factor (knowledge) and two-factor (attitude and practice) models fit the data compared to the unidimensional model. The results confirmed the factorial structure proposed by Goni et al. (2020) and Mohammd Dauda Goni et al. (2020). Furthermore, the good-of-fit of the unidimensional model was also satisfactory and provided alternative representations of the structure. All questionnaire items have a significant value of $\lambda$, at a $\mathrm{p}<$ 0.05 significance level. A complete summary of fit indices for confirmatory factor models is presented in Table 2.

\section{Unidimensionality and Local Independence Assumptions}

The first assumption test for unidimensionality was carried out using Principal Component Analysis of Residuals (Chou \& Wang, 2010). As per the recommendation of Linacre, the minimum variance explained should exceed 30\% (J. M. Linacre, 1998). The 
Table 2. Fit indices for confirmatory factor models for draft SKAPCOV-19 questionnaire

\begin{tabular}{|c|c|c|c|c|c|c|c|}
\hline \multirow[t]{2}{*}{ Domains } & \multirow[t]{2}{*}{ No of items } & \multirow[t]{2}{*}{ Models } & \multicolumn{5}{|c|}{ Goodness of fit indices } \\
\hline & & & $x^{2} / \mathrm{df}$ & GFI & AGFI & SRMR & RMSEA \\
\hline \multirow[t]{2}{*}{ Knowledge } & 18 & Unidimensional & 1.871 & 0.93 & 0.91 & 0.007 & 0.047 \\
\hline & & Four-factor & 1.765 & 0.94 & 0.92 & 0.007 & 0.044 \\
\hline \multirow[t]{2}{*}{ Attitude } & 6 & Unidimensional & 0.076 & 0.99 & 0.98 & 0.004 & 0.000 \\
\hline & & Two-factor & 0.525 & 0.99 & 0.99 & 0.004 & 0.000 \\
\hline \multirow[t]{2}{*}{ Practice } & 12 & Unidimensional & 2.862 & 0.94 & 0.90 & 0.016 & 0.069 \\
\hline & & Two-factor & 2.418 & 0.95 & 0.92 & 0.015 & 0.060 \\
\hline
\end{tabular}

Table 3. Reliability and separation indices for draft SKAPCOV-19 questionnaire

\begin{tabular}{llcc}
\hline Constructs & ID item & \multicolumn{2}{c}{ Item measure } \\
\cline { 3 - 4 } & & Reliability & Separation \\
\hline Knowledge & Items 1-18 & 0.98 & 7.52 \\
Attitude & Items 19-24 & 0.97 & 6.12 \\
Practice & Items 25-36 & 0.99 & 9.29 \\
\hline
\end{tabular}

results of the analysis of the SKAPCOV-19 questionnaire demonstrated unidimensionality, since the variance explained was above the minimum for all three domains: $34.4 \%$ (eigenvalue 9.46) for knowledge, 50.8\% (eigenvalue 6.20) for attitudes, and 39.4\% (eigenvalue 7.81 ) for practices. This finding is in line with the results of CFA analysis, as noted earlier.

The second assumption test was for local independence, i.e., that the performance of one item does not depend on the performance of other items (Lipovetsky, 2020). This test is based on the value of the raw residual correlation between pairs of items, with values close to 0 being ideal. An upper limit of 0.30 can be reached without violating the assumption of local independence (Christensen et al., 2017). In this study, none of the items from the three domains exceeded 0.30 . In other words, all three domains have fulfilled this assumption test. The results of the assumption tests showed that the SKAPCOV-19 questionnaire measurement model was proven to be unidimensional and did not violate the test of local independence. Further analysis can thus be pursued.

\section{Reliability for the Draft SKAPCOV-19 Questionnaire}

The item reliability for all three domains (knowledge, attitudes, and practice) was $>0.90$, with a separation index value $>0.20$. This means that the 36 items in the SKAPCOV-19 questionnaire have unique qualities, as is evident from the separation index values that are three to four times greater than the threshold. A summary of the item reliability and separation indices for the draft questionnaire is presented in Table 3.

\section{Fit statistics for the Draft SKAPCOV-19 Questionnaire}

Based on the criteria for the fit index used to ensure acceptability, four items were identified as misfits with the model. Two of these were in the attitude domain (A2 and A6) and another two in the practice domain (P1 and P4). The misfit index values with the model were marked. Meanwhile, all 18 items in the knowledge domain obtained fit index values. No items were deleted since all four items detected (P1, P4, A2, and A6) have misfits in only one parameter. Thus, all 36 questionnaire items were retained. Complete item questionnaire and data for knowledge, attitude, and practice domains are provided in Tables 4, 5, and 6, respectively.

Table 4. Items fit and misfit indices for knowlegde domains

\begin{tabular}{|c|c|c|c|c|c|c|}
\hline Factors & & $\begin{array}{c}\text { Infit } \\
\text { MNSQ }\end{array}$ & $\begin{array}{c}\text { Outfit } \\
\text { MNSQ }\end{array}$ & $\begin{array}{l}\text { Infit } \\
\text { Zstd }\end{array}$ & $\begin{array}{c}\text { Outfit } \\
\text { Zstd }\end{array}$ & PTMEA \\
\hline \multirow[t]{4}{*}{ Etiology } & COVID-19 is a disease... & & & & & \\
\hline & K1. Caused by Coronavirus & 1.07 & 1.19 & 1.36 & 1.94 & 0.33 \\
\hline & K2. With main clinical symptoms are fever and dry cough & 0.98 & 0.89 & -0.08 & -0.34 & 0.34 \\
\hline & K3. Also show no symptoms & 0.93 & 1.00 & -0.34 & 0.10 & 0.34 \\
\hline \multirow[t]{5}{*}{ Risk group } & The following persons are at an increased risk of COVID-19 & & & & & \\
\hline & K4. Senior citizens aged 65 and older & 1.08 & 0.96 & 0.93 & -0.22 & 0.33 \\
\hline & K5. Have chronic diseases or cormobid & 1.02 & 0.97 & 0.22 & -0.12 & 0.36 \\
\hline & K6. Except children and teenagers & 1.00 & 0.95 & 0.08 & -0.07 & 0.32 \\
\hline & K7. Have a weak immune system & 0.99 & 1.01 & -0.16 & 0.13 & 0.41 \\
\hline \multirow{7}{*}{ Transmission } & COVID-19 are spread by: & & & & & \\
\hline & K8. Infected person without symptoms & 0.93 & 0.84 & -0.50 & -0.72 & 0.39 \\
\hline & K9. Respiratory droplets of infected person & 1.10 & 1.05 & 1.28 & 0.43 & 0.31 \\
\hline & K10. The dead bodies of infected person & 1.00 & 1.06 & 0.10 & 0.63 & 0.39 \\
\hline & K11. The buried dead bodies of infected person & 1.07 & 1.11 & 1.07 & 1.13 & 0.34 \\
\hline & K12. Can not penetrate cloth masks & 0.95 & 0.92 & -1.12 & -0.96 & 0.45 \\
\hline & K13. Through objects, it is not airborne & 1.06 & 1.06 & 1.50 & 0.91 & 0.37 \\
\hline
\end{tabular}


Table 4 (continued). Items fit and misfit indices for knowledge domains

\begin{tabular}{|c|c|c|c|c|c|c|}
\hline Factors & & $\begin{array}{c}\text { Infit } \\
\text { MNSQ }\end{array}$ & $\begin{array}{c}\text { Outfit } \\
\text { MNSQ }\end{array}$ & $\begin{array}{l}\text { Infit } \\
\text { Zstd }\end{array}$ & $\begin{array}{c}\text { Outfit } \\
\text { Zstd }\end{array}$ & PTMEA \\
\hline \multirow[t]{6}{*}{ Preventions } & The following practices can help protect you from COVID19: & & & & & \\
\hline & K14. There is no effective drug for COVID-19 & 0.85 & 0.61 & -0.87 & -1.53 & 0.43 \\
\hline & K15. Avoid going to crowded places & 0.85 & 1.33 & -0.54 & 0.82 & 0.34 \\
\hline & K16. Avoid travel across cities & 0.87 & 0.78 & -0.49 & -0.47 & 0.36 \\
\hline & K17. Not touching the face & 0.94 & 0.76 & -0.36 & -0.99 & 0.38 \\
\hline & K18. Isolation and treatment of infected person & 0.87 & 0.67 & -0.30 & -0.55 & 0.34 \\
\hline
\end{tabular}

Table 5. Items fit and misfit indices for attitude domains

\begin{tabular}{|c|c|c|c|c|c|c|}
\hline Factors & & $\begin{array}{c}\text { Infit } \\
\text { MNSQ }\end{array}$ & $\begin{array}{l}\text { Outfit } \\
\text { MNSQ }\end{array}$ & $\begin{array}{l}\text { Infit } \\
\text { Zstd }\end{array}$ & $\begin{array}{c}\text { Outfit } \\
\text { Zstd }\end{array}$ & PTMEA \\
\hline \multirow{4}{*}{$\begin{array}{l}\text { Barriers to } \\
\text { compliance }\end{array}$} & Handling COVID-19 will be more difficult if people or the com & imunity: & & & & \\
\hline & A1. Not keeping up the information related to preventions & 1.33 & 0.94 & 1.61 & -0.15 & 0.52 \\
\hline & A2. No longer need to worry about contracting COVID-19 & 0.88 & 1.48 & -1.52 & 3.54 & 0.66 \\
\hline & A3. Influence by negative news & 1.09 & 0.94 & 0.99 & -0.52 & 0.67 \\
\hline \multirow{4}{*}{$\begin{array}{l}\text { Self- } \\
\text { motivations }\end{array}$} & I feel that person experiencing the symptoms or person infecte & d should & & & & \\
\hline & A4. compliance the health protocols such as wearing the mask & 1.13 & 0.77 & 0.75 & -0.99 & 0.59 \\
\hline & A5. Isolate themselves during 14 days & 1.28 & 0.74 & 0.93 & -0.40 & 0.51 \\
\hline & $\begin{array}{l}\text { A6. Motivated to increasingly implement COVID-19 } \\
\text { prevention measures and ensuring a healthy life }\end{array}$ & 0.99 & 2.44 & 0.12 & 1.50 & 0.44 \\
\hline
\end{tabular}

Table 6. Items fit and misfit indices for knowledge domains

\begin{tabular}{|c|c|c|c|c|c|c|}
\hline \multicolumn{2}{|l|}{ Factors } & $\begin{array}{c}\text { Infit } \\
\text { MNSQ }\end{array}$ & $\begin{array}{c}\text { Outfit } \\
\text { MNSQ }\end{array}$ & \multirow[t]{2}{*}{$\begin{array}{l}\text { Infit } \\
\text { Zstd }\end{array}$} & \multirow[t]{2}{*}{$\begin{array}{c}\text { Outfit } \\
\text { Zstd }\end{array}$} & \multirow[t]{2}{*}{ PTMEA } \\
\hline Prevention & In a crowded or public place: & & & & & \\
\hline \multirow[t]{9}{*}{ Practices } & P1. I wear mask & P1 & 1.39 & 0.86 & 2.77 & -0.63 \\
\hline & P2. I keep a distance (physical distancing) & $\mathrm{P} 2$ & 1.18 & 0.80 & 1.51 & -1.10 \\
\hline & P3. I use hand sanitizer & P3 & 1.11 & 1.01 & 1.57 & 0.19 \\
\hline & After going to a crowded or public place: & & & & & \\
\hline & P4. I wash my hand and take a bath & $\mathrm{P} 4$ & 0.92 & 1.37 & -1.12 & 5.13 \\
\hline & P5. I Change my clothes & P5 & 0.99 & 0.93 & -0.08 & -0.76 \\
\hline & As a student, I carried out a campaign to preve & $t$ the spread of covid- & 19 throug & & & \\
\hline & P6. My social media & P6 & 1.07 & 1.09 & 1.06 & 1.12 \\
\hline & P7. Provides a direct example in daily activity & P7 & 0.90 & 0.64 & -0.50 & -1.20 \\
\hline Health & I eat fruits and vegetables & P8 & 0.91 & 0.79 & -0.88 & -136 \\
\hline \multirow[t]{4}{*}{ Lifestyle } & I get enough rest & P9 & 1.13 & 1.05 & 1.65 & 0.53 \\
\hline & I exercising routinely & P10 & 0.90 & 0.98 & -1.56 & -0.33 \\
\hline & I take vitamins or supplements & P11 & 1.08 & 1.00 & 1.15 & 0.02 \\
\hline & I clean my house more frequently & P12 & 0.92 & 0.68 & -0.52 & -1.37 \\
\hline Category & Andrich threshold Observed count (\%) & Observed average & \multicolumn{2}{|c|}{ Infit } & \multicolumn{2}{|c|}{ Outfit } \\
\hline Disagree & $65(3 \%)$ & -0.28 & \multicolumn{2}{|c|}{1.49} & \multicolumn{2}{|c|}{1.86} \\
\hline Don't know & $262(11 \%)$ & 0.94 & \multicolumn{2}{|c|}{0.76} & \multicolumn{2}{|c|}{1.14} \\
\hline Agree & $2007(86 \%)$ & 1.03 & \multicolumn{2}{|c|}{1.03} & \multicolumn{2}{|c|}{1.14} \\
\hline
\end{tabular}

\section{Rating Scale Diagnostics}

This measurement is used to evaluate the clarity and ease of interpretation of the response sets used in the SKAPCOV-19 questionnaire (Kim \& Kyllonen, 2006). An analysis was carried out on the factors associated with attitude and practice, since these had three rating scales that could be confusing, while the factors associated with knowledge involved a simpler true or false dichotomy. The number of endorsements, the shape of the distribution of endorsements, and the MNSQ statistics for each item were diagnosed. The results of the analysis in the attitude domain (Table 7) show a negative skewness in the distribution of $3 \%$ in the first category (disagree), while the practice domain (Table 8 ) shows a negatively skewed distribution of $6 \%$ in the first category (never). These two results are relative to the Andrich threshold which moves from none to negative and continues to lead to positive, showing that the options provided are valid and sequential. These three choices 
Table 8. Rating scale diagnostic table for practices

\begin{tabular}{lccccc}
\hline Category & Andrich threshold & Observed count $(\%)$ & Observed average & Infit & Outfit \\
\hline Never & None & $284(6 \%)$ & -0.02 & 1.19 & 1.28 \\
Sometimes & -1.10 & $1276(27 \%)$ & 0.98 & 0.90 & 0.71 \\
Often & 1.10 & $3108(67 \%)$ & 2.90 & 1.04 & 1.17 \\
\hline
\end{tabular}

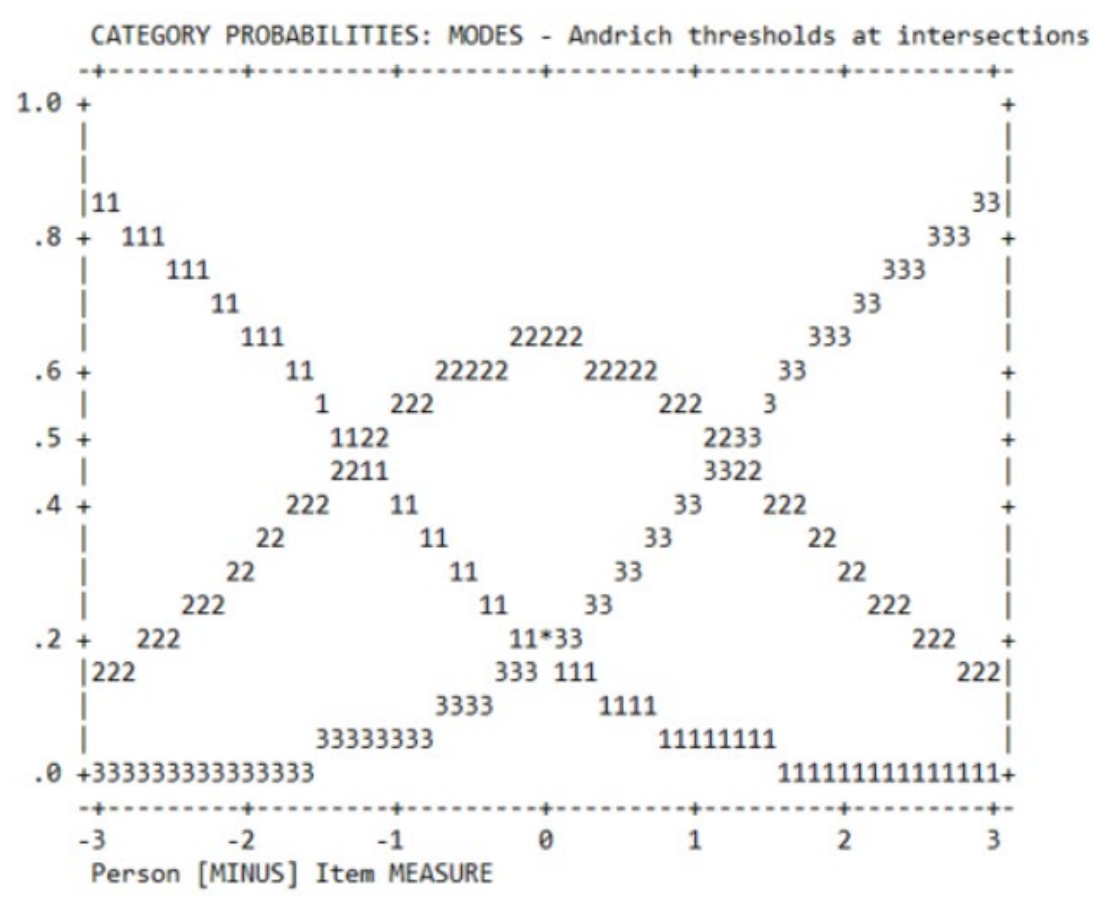

Figure 1. Category response curve of attitude

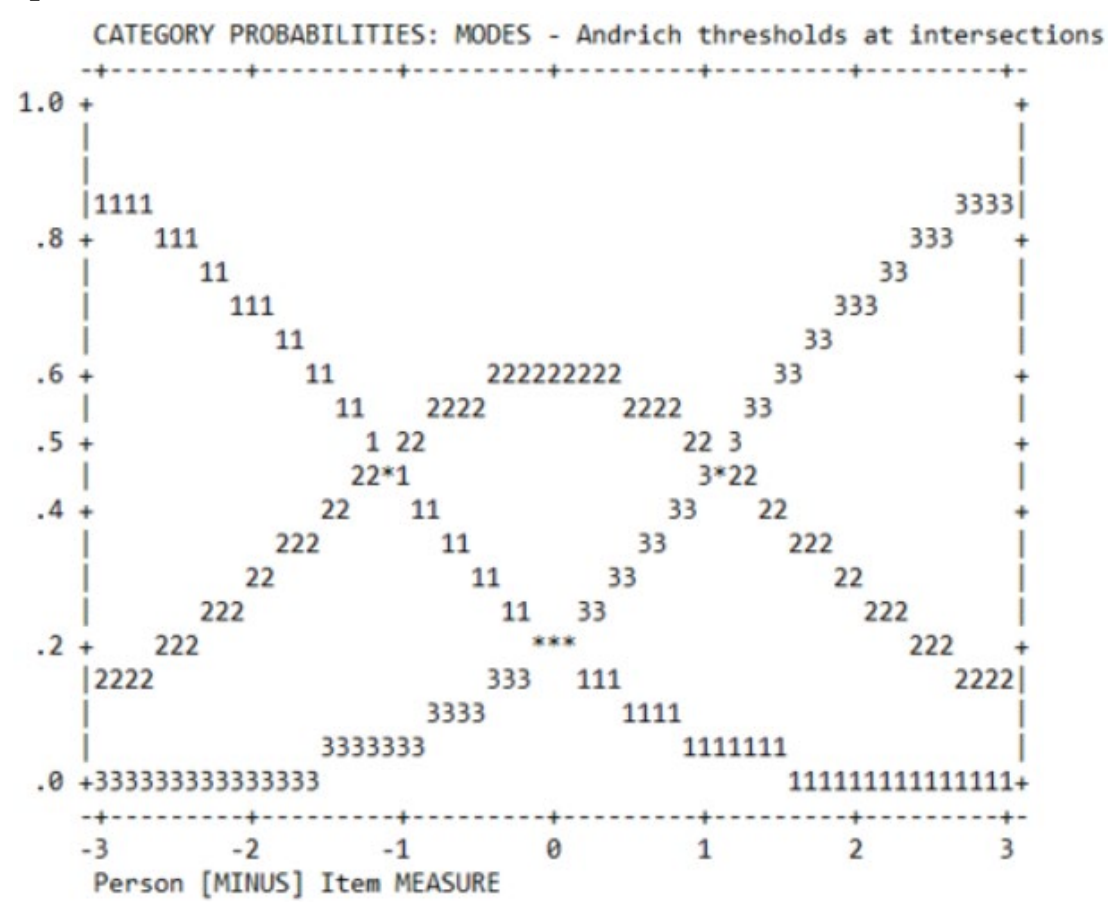

Figure 2. Category response curve of practices

indicate that respondents were able to ascertain the difference in scales provided, as is evident from the increasing logit. This conclusion is supported by the results of infit and outfit MNSQ analysis, the values of which are within the range of \pm 2 .
The scale analysis for the attitude domain (Figure 1) and for the practice domain (Figure 2) represents the response category function in the SKAPCOV-19 questionnaire and shows the recommended pattern in both cases. Thus, it can be concluded that the response series of the SKAPCOV-19 questionnaire functions properly. 


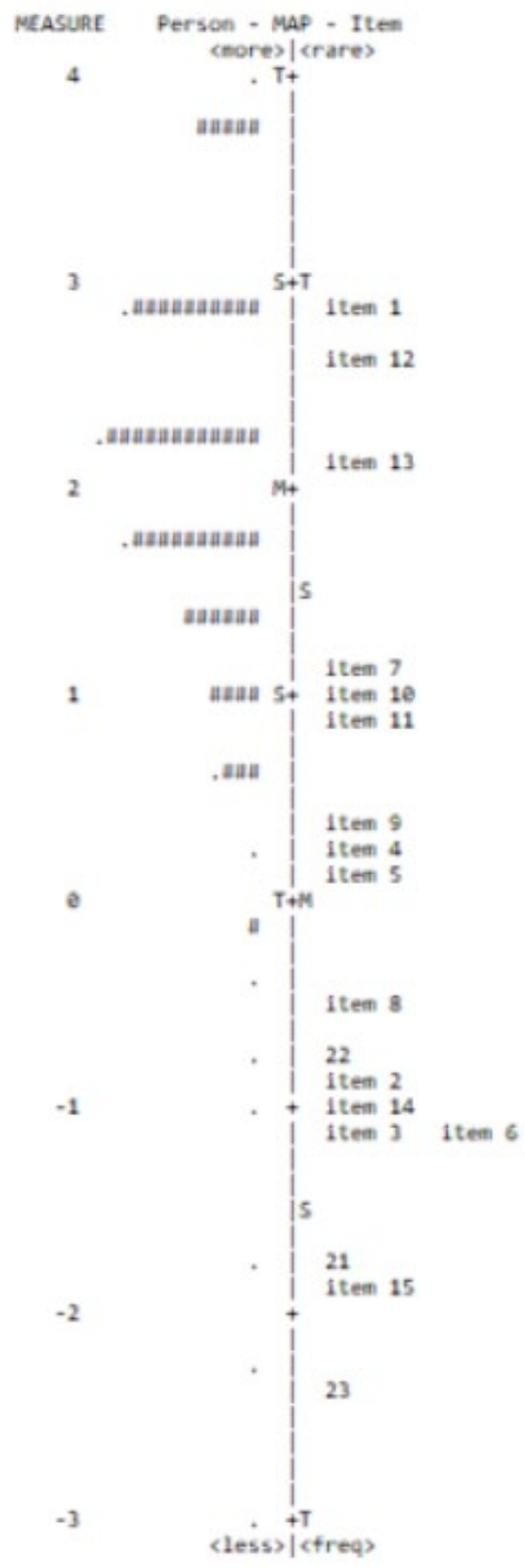

(a)

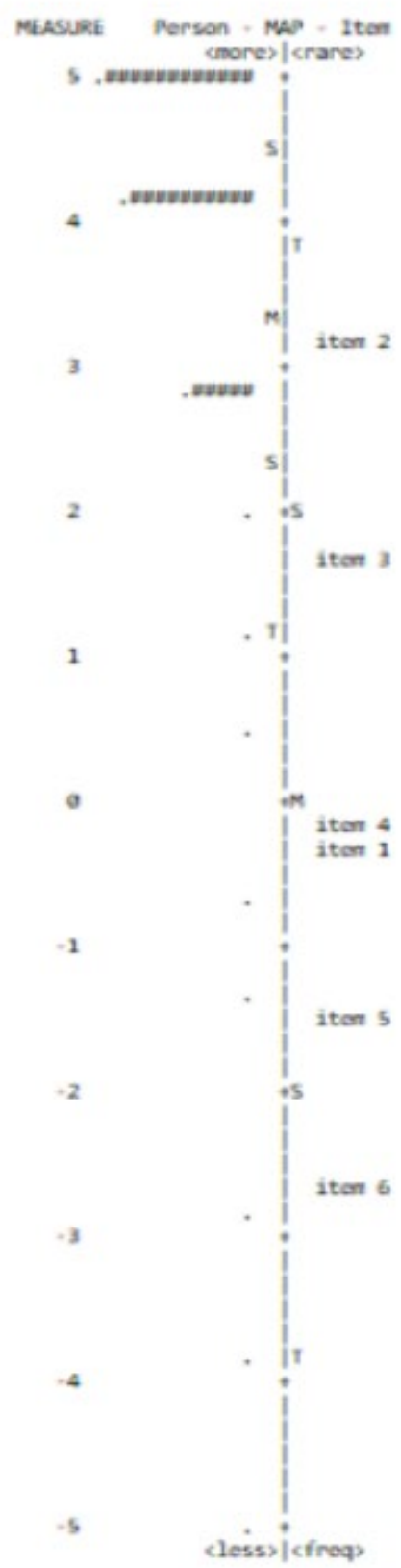

(b)

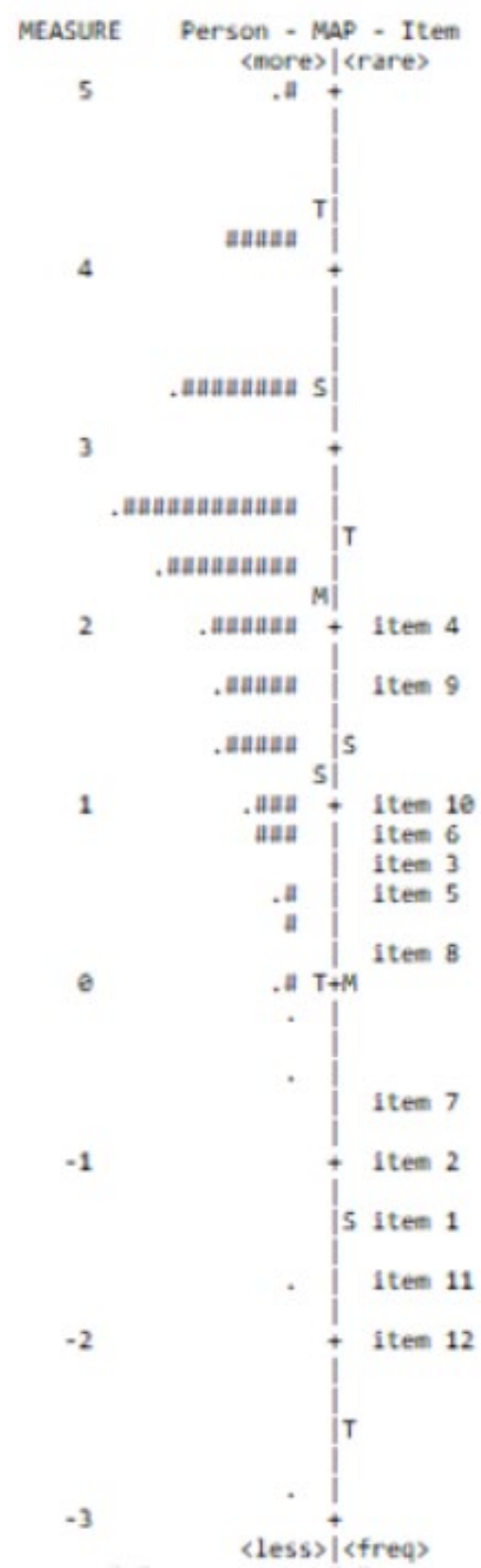

(c)

Figure 3. Wright Map of SKAPCOV-19 Questionnaire representing direct comparison of person dispersion and item distribution. (a) knowledge, (b) attitude, (c) practice.

\section{Wright Map}

This analysis was carried out to evaluate the items in the SKAPCOV-19 questionnaire, identifying which were the easiest and which were the most difficult to answer. Figure 3(a) of the knowledge domain shows that the most difficult item to answer was number 1 , while the easiest was number 15. Figure 3(b) of the attitude domain shows that the least approved item was number 2 and the most approved was number 6 . Finally, Figure 3 (c) of the behavioral factors indicates that the least frequent behavior was number 4, while the most frequent was number 12 .

\section{Test Information Function}

Figure 4 (a-c) shows that, at a moderate ability level $(\operatorname{logit}$ value $=0)$, the information obtained by the measurements is high. A different result is obtained if the logit is lower or higher, in which case the value of the obtained information is lower. The results of the analysis of the test information function show that the items in the SKAPCOV-19 questionnaire across all three domains (KAP) produce optimal results when given to individuals with moderate ability. This result also indicates that the questionnaire can be used for formative assessment. 


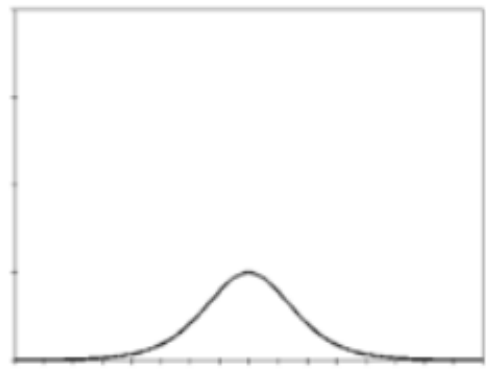

(a)

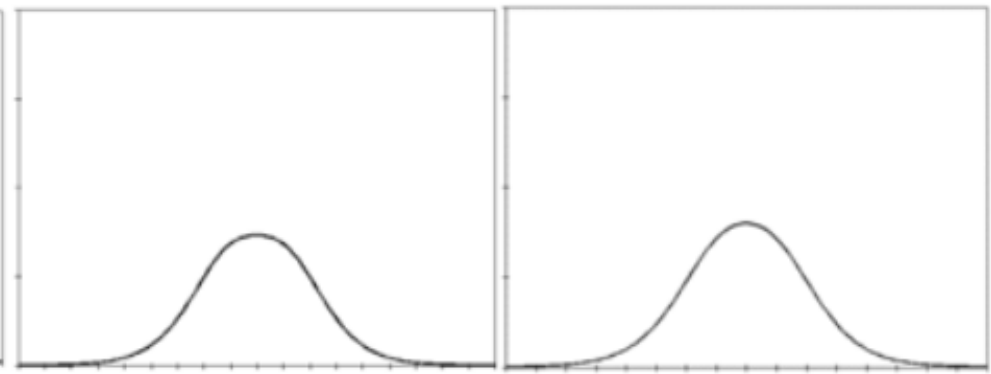

(b) (c)

Figure 4. Test information function of SKAPCOV-19 Questionnaire: (a) knowledge, (b) attitude, (c) practice.

\section{DISCUSSION}

The increasingly extensive spread of COVID-19 indicates the need for KAP measurement on the effective prevention of the disease. This research represents the first attempt to develop a questionnaire capable of satisfying this need, at least for students. The previous KAP measurements of which we are aware have suffered from serious drawbacks (Fauzi et al., 2020; Mohd Hanafiah \& Wan, 2020; Olapegba \& Ayandele, 2020; Wadood et al., 2020; Zhong et al., 2020). For example, face validity and content validity have not been ensured for each item in the questionnaire, rigorous psychometric measurements have not been carried out, and questionnaire items remain limited. Furthermore, some of the measurements made were still in the context of public KAP (Mohd Hanafiah \& Wan, 2020; Olapegba \& Ayandele, 2020; Zhong et al., 2020), rather than being limited to college students (Fauzi et al., 2020; Wadood et al., 2020). Conversely, this study reports in detail the stages of designing and developing a questionnaire tailored to students' KAP toward the prevention of COVID-19 (SKAPCOV-19), and this also tests its validity using the CFA and RASCH model. The overall results are quite satisfactory. In addition, the investigation of the construct validity of the SKAPCOV-19 questionnaire using CFA provided evidence that not only four and two-factor models have good quality of goodness-of-fit indices, but unidimensional models do as well. This finding is in line with the results of unidimensionality assumptions using the RASCH model.

Expert validation with CVI values greater than 0.80 indicates that this instrument should be suitable for measuring students' KAP toward the prevention of COVID-19 (Burns et al., 2008; DeVon et al., 2007). Accordingly, all 36 items were retained because they were considered to be particularly applicable to measuring students' KAP. The suggestions and recommendations given by experts all pertained to clarity of sentence structure and language, with no serious implications for content validity. All questionnaire items were thus maintained with a number of improvements to ensure refinement in face and content validity. This step illustrates how carefully the appropriate selection of variables in instrument construction must be carried out (Ismail et al., 2020). Face validity ensures that items are presented in a simple manner which is easily understood by prospective respondents, while content validity ensures that the questionnaire items adequately represent student's KAP toward the prevention of the spread of COVID-19.

This study demonstrates the value of $\mathrm{RASCH}$ in assessing and validating questionnaire items (Golino et al., 2014; Müller et al., 2015). The findings of this study indicate that the SKAPCOV-19 questionnaire items were generally adequate and appropriate for measuring student's KAP toward the prevention of COVID-19. Analysis using the RASCH model shows that the SKAPCOV-19 questionnaire items have very high reliability (Bond \& Fox, 2007), with real item reliability (real RMSE), $r=0.97-0.99$. This ensures that the questionnaire has a potentially broad application (Gerbing \& Anderson, 1988). Similar observations on the separation index show that the relevant values for all the three domains are good (Bond \& Fox, 2007). In other words, the items in this questionnaire are divided into two or more different groups (Kook \& Varni, 2008). This suggests that the SKAPCOV-19 questionnaire is capable of differentiating students according to their response rates. This assumption is supported by the high PTMEA Corr value index.

Regardless of whether a small sample size can provide a good research output (Bond \& Fox, 2007), it is assumed that the sample size in this study is considered large enough and has positively influenced the values of the item reliability and separation indices (Golino et al., 2014; Kjellström et al., 2016). The results of this study draw attention to psychometric measurement using the RASCH model by considering a sample size within the recommended range of 250-500 respondents (Hagell \& Westergren, 2016; J. Linacre, 1994) to achieve 95\% confidence and an item calibration of 0.00 logits. Even the most recent studies regarding the validation of KAP questionnaires on health using the RASCH model have shown that assessment and validation involving 100 respondents did not provide satisfactory results, and thus a larger sample is recommended (Ismail et al., 2020). An increase in sample size can strengthen parameter estimation as has been reported in a number of previous studies (He \& Wheadon, 2013; Smith et al., 2008). 
Based on the value index used to interpret the output of the RASCH model (Bond \& Fox, 2007), four items should have been omitted. Two of these were in the attitude domain, and two in the practice domain. However, applying the rule that items with a misfit of only one parameter can be tolerated, and given that the removal of a large number of items may negatively impact item reliability (Ismail et al., 2020), it was decided to retain all four items. The overall results of the MNSQ and ZSTD fit indices on all 36 questionnaire items (Table 2) were mostly within the acceptable range. In terms of PTMEA Corr values, all questionnaire items were found to be positive and high, showing a strong correlation and not contradicting the model construct (J. Linacre, 1994).

The SKAPCOV-19 questionnaire was developed with three choice or response categories, which showed an adequate performance as indicated by three parameters. Specifically, the Andrich threshold and logit (observed average) values of the response categories increased monotonously and moved in the expected direction, while the values of the three response categories show that infit and outfit MNSQ fit statistics were acceptable. This is one of the various benefits of measurements of assessment and validation using the RASCH model (Andrich \& Marais, 2019; Tennant \& Conaghan, 2007).

Regarding the students' KAP level, many students in Indonesia have a bad understanding, behave inappropriately, and act negatively in the COVID-19 outbreak situation (Saefi et al., 2020). The length of education (spending years in universities and majors) can be seen as a factor in this unwanted situation. Several other studies have also informed that many students do not believe in scientific findings (Kabat, 2017; Lewandowsky et al., 2016). The low level of KAP and students' distrust of scientific findings indicate that the science learning process is not optimal in most schools.

In connection with the current pandemic conditions, the education system should be able to design a curriculum and learning process that can empower students' scientific thinking habits (Erduran, 2020). The implementation of science learning should also equip students to understand the causes of a pandemic and know what actions are needed to help the government overcome the outbreak (Grace \& Bay, 2011; Jacque et al., 2016). Science education should also be able to act as a bulwark against disinformation and fake news related to the disease (Höttecke \& Allchin, 2020; Jones-Jang et al., 2019). Science education is also expected to be able to rectify and prevent students from engaging in harmful practices and increase their positive attitudes in order to minimize negative impacts during the outbreak.

The existence of studies that analyze and map student KAP levels is an important step towards evaluating and improving the quality and role of science education during an outbreak. The availability of validated KAP instruments is a necessity for researchers to examine these conditions. In this position, the SKAPCOV-19 questionnaire that has been validated in this study can be used to explore the needs, problems, and influences involved in the implementation of science education. In addition, the questionnaire can be used as a tool to identify which policies need to be prioritized in science education implementation, especially during the COVID-19 pandemic. This instrument can also be used to analyze the effectiveness of the learning interventions given by researchers to students' KAP level changes. Once again, we emphasize that without a valid questionnaire, the data obtained will be less reliable, which in turn may lead to inappropriate recommendations for educational interventions.

Apart from the validation results that have been reported, certain limitations of this study should be noted. Even though the sample was obtained from 10 universities using a random sampling method, all participants are Indonesian citizens. Combining the CFA and RASCH analyses can help to overcome this problem as they are independent of the sample involved and allow for generalizations. However, further research is recommended to involve participants from various races and countries so that the population becomes heterogeneous.

\section{CONCLUSION}

This present study has validated a new instrument to measure KAP toward the prevention of COVID-19 among university students. The use of CFA and RASCH model analysis in confirming the accuracy of each item in the SKAPCOV-19 questionnaire was highlighted. All items and sections of the questionnaire showed acceptable psychometric properties and good reliability. Although the results of Rascy's analysis inform that the questionnaire fulfills the undimensionality assumption to produce a single factor, the CFA results inform that several subscales produce separate factors. Finally, The SKAPCOV-19 questionnaire consisted of 3 parts, comprising 36 items (18 four factor items of knowledge domain, 6 two factors items of attitude domain, and 12 two factor items of practice domain).

Based on the analysis that has been done the SKAPCOV-19 questionnaire can be used to measure student KAP toward COVID-19. The use of this questionnaire can facilitate researchers to map and evaluate the role of science education in preparing students to face outbreaks which are actually natural phenomena studied in science lessons. The use of this questionnaire is also recommended to measure changes in student KAP after certain educational policies or learning interventions are implemented.

\section{ACKNOWLEDGEMENT}

We would like to thank the Lembaga Pengembangan Publikasi Ilmiah UMM for providing support and 
facilities during the process of drafting this manuscript. In addition, we would like to thank our colleagues from Universitas Negeri Malang, Universitas Muhammadiyah Malang, Universitas Islam Jember, Universitas Jember, Universitas Islam Negeri Walisongo Semarang, Universitas Islam Negeri Maulana Malik Ibrahim Malang, Institut Agama Islam Negeri Kerinci, and Institut Teknologi Sepuluh Nopember for their collaboration, as well as all the participants in the data collection.

\section{REFERENCES}

Albright, A. E., \& Allen, R. S. (2018). HPV misconceptions among college students: The role of health literacy. Journal of Community Health, 43(6), 1192-1200. https://doi.org/10.1007/s10900-0180539-4

Andrich, D., \& Marais, I. (2019). Review of Principles of Test Analysis Using Rasch Measurement Theory. In A Course in Rasch Measurement Theory (pp. 327-342). https:/ / doi.org/10.1007/978-981-13-7496-8_29

Annas, G. J., Mariner, W. K., \& Parmet, W. E. (2008). Pandemic Preparedness: The Need for a Public Health Approach.

Ashrafi-Rizi, H., \& Kazempour, Z. (2020). Information typology in coronavirus (COVID-19) crisis; a commentary. Archives of Academic Emergency Medicine, $8(1)$,

e19. https:/ / doi.org/10.22037/aaem.v8i1.591

Bakhtiar, T. (2016). Optimal intervention strategies for cholera outbreak by education and chlorination. IOP Conference Series: Earth and Environmental Science, 31(1). https://doi.org/10.1088/17551315/31/1/012022

Barennes, H., Harimanana, A. N., Lorvongseng, S., Ongkhammy, S., \& Chu, C. (2010). Paradoxical risk perception and behaviours related to Avian Flu outbreak and education campaign, Laos. BMC Infectious Diseases, 10(March 2006). https: / / doi.org/10.1186/1471-2334-10-294

Bond, T., \& Fox, C. M. (2007). Applying the Rasch Model: Fundamental Measurement in the Human Sciences, Second Edition (2 edition).

Burns, K. E. A., Duffett, M., Kho, M. E., Meade, M. O., Adhikari, N. K. J., Sinuff, T., Cook, D. J., \& Group, for the A. (2008). A guide for the design and conduct of self-administered surveys of clinicians. Canadian Medical Association Journal, 179(3), 245-252. https:/ / doi.org/10.1503/cmaj.080372

Chou, Y.-T., \& Wang, W.-C. (2010). Checking Dimensionality in Item Response Models with Principal Component Analysis on Standardized Residuals. Educational and Psychological Measurement, 70(5), 717-731. https://doi.org/ $10.1177 / 0013164410379322$
Christensen, K. B., Makransky, G., \& Horton, M. (2017). Critical values for Yen's Q3: Identification of local dependence in the Rasch model using residual correlations. Applied Psychological Measurement, 41(3), 178-194. https://doi.org/10.1177/01466216 16677520

Creswell, J. W. (2012). Educational research: Planning, conducting, and evaluating quantitative and qualitative research. In Educational Research (4th ed., Vol. 4). Pearson Education.

DeVon, H. A., Block, M. E., Moyle-Wright, P., Ernst, D. M., Hayden, S. J., Lazzara, D. J., Savoy, S. M., \& Kostas-Polston, E. (2007). A Psychometric Toolbox for Testing Validity and Reliability. Journal of Nursing Scholarship, 39(2), 155-164. https:/ / doi.org/10.1111/j.1547-5069.2007.00161.x

Dörnyei, Z. (2003). Questionnaires in Second Language Research: Construction, Administration, and Processing. Lawrence Erlbaum Associates.

Easton, M. (2020, June 18). Social media "spreading virus conspiracy theories." BBC News. Retrieved from https: / / www.bbc.com/news/uk-53085640

Erduran, S. (2020). Science education in the era of a pandemic. Science E Education, 29(2), 233-235. https:// doi.org/10.1007/s11191-020-00122-w

Fauzi, A., Husamah, H., Miharja, F. J., Fatmawati, D., Permana, T. I., \& Hudha, A. M. (2020). Exploring COVID-19 Literacy Level among Biology Teacher Candidates. Eurasia Journal of Mathematics, Science and Technology Education, 16(7), em1864. https:/ / doi.org/10.29333/ ejmste/8270

Gerbing, D. W., \& Anderson, J. C. (1988). An Updated Paradigm for Scale Development Incorporating Unidimensionality and Its Assessment. Journal of Marketing Research, 25(2), 186-192. https:// doi.org/10.1177/002224378802500207

Golino, H. F., Gomes, C. M. A., Commons, M. L., \& Miller, P. M. (2014). The construction and validation of a developmental test for stage identification: Two exploratory studies. Behavioral Development Bulletin, 19(3), 37-54. https:/ / doi.org/10.1037/h0100589

Goni, Mohammd Dauda, Naing, N. N., Hasan, H., WanArfah, N., Deris, Z. Z., Arifin, W. N., Baaba, A. A., \& Njaka, S. (2020). A Confirmatory Factor Analysis of the knowledge, attitude and practice questionnaire towards prevention of Respiratory tract infections during Hajj and Umrah [Preprint]. In Review. https:/ / doi.org/10.21203/rs.3.rs-18609/v1

Goni, M. D., Hasan, H., Naing, N. N., Wan-Arfah, N., Deris, Z. Z., Arifin, W. N., \& Baaba, A. A. (2019). Assessment of knowledge, attitude and practice towards prevention of respiratory tract infections among hajj and umrah pilgrims from Malaysia in 2018. International Journal of Environmental Research 
and Public Health, 16(22), 1-11. https:// doi.org/10.3390/ijerph16224569

Goni, M. D., Naing, N. N., Hasan, H., Wan-Arfah, N., Deris, Z. Z., Arifin, W. N., Hussin, T. M. A. R., Abdulrahman, A. S., Baaba, A. A., \& Arshad, M. R. (2020). Development and validation of knowledge, attitude and practice questionnaire for prevention of respiratory tract infections among Malaysian Hajj pilgrims. BMC Public Health, 20(1), 189. https:// doi.org/10.1186/s12889-020-8269-9

Grace, M., \& Bay, J. L. (2011). Developing a pedagogy to support science for health literacy. Asia-Pacific Forum on Science Learning and Teaching, 12(2), 1-13.

Gugus Tugas Percepatan Penanganan COVID-19. (2020). Materi Edukasi-Pengantar | Gugus Tugas Percepatan Penanganan COVID-19. In Covid19.go.id.

Hagell, P., \& Westergren, A. (2016). Sample Size and Statistical Conclusions from Tests of Fit to the Rasch Model According to the Rasch Unidimensional Measurement Model (Rumm) Program in Health Outcome Measurement. Journal of Applied Measurement, 17(4), 416-431.

He, Q., \& Wheadon, C. (2013). The effect of sample size on item parameter estimation for the partial credit model. International Journal of Quantitative Research in Education, 1(3), 297-315. https:/ / doi.org/10.1504 /IJQRE.2013.057692

Höttecke, D., \& Allchin, D. (2020). Reconceptualizing nature-of-science education in the age of social media. Science Education, 104(4), 641-666. https:// doi.org/10.1002/sce.21575

Hu, Z., Song, C., Xu, C., Jin, G., Chen, Y., Xu, X., Ma, H., Chen, W., Lin, Y., Zheng, Y., Wang, J., hu, zhibin, Yi, Y., \& Shen, H. (2020). Clinical Characteristics of 24 Asymptomatic Infections with COVID-19 Screened among Close Contacts in Nanjing, China. https:/ / doi.org/10.1101/2020.02.20.20025619

Ismail, N. E., Jimam, N. S., Dapar, M. L. P., \& Ahmad, S. (2020). Validation and Reliability of Healthcare Workers' Knowledge, Attitude, and Practice Instrument for Uncomplicated Malaria by Rasch Measurement Model. Frontiers in Pharmacology, 10, 1521. https:/ / doi.org/10.3389/fphar.2019.01521

Jacque, B., Koch-Weser, S., Faux, R., \& Meiri, K. (2016). Addressing health literacy challenges with a cutting-edge infectious disease curriculum for the high school biology classroom. Health Education $\mathcal{E}$ Behavior, 43(1), 43-53. https://doi.org/10.1177/ 1090198115596163

Jones-Jang, S. M., Mortensen, T., \& Liu, J. (2019). Does media literacy help identification of fake news? Information literacy helps, but other literacies don't. American Behavioral Scientist,
000276421986940.

https:/ / doi.org/10.1177/0002764219869406

Jones-Konneh, T. E. C., Murakami, A., Sasaki, H., \& Egawa, S. (2017). Intensive education of health care workers improves the outcome of ebola virus disease: Lessons learned from the 2014 outbreak in Sierra Leone. Tohoku Journal of Experimental Medicine, 243(2), 101-105. https:/ / doi.org/10.1620/ tjem.243.101

Kabat, G. C. (2017). Taking distrust of science seriously. EMBO Reports, 18(7), 1052-1055. https:/ / doi.org/10.15252/embr.201744294

Kain, T., \& Fowler, R. (2019). Preparing intensive care for the next pandemic influenza. Critical Care, 23(1), 19. https:// doi.org/10.1186/s13054-019-2616-1

Karlsen, H., Mehli, L., Wahl, E., \& Staberg, R. L. (2015). Teaching outbreak investigation to undergraduate food technologists. British Food Journal, 117(2), 766778. https:/ / doi.org/10.1108/BFJ-02-2014-0062

Kim, S., \& Kyllonen, P. C. (2006). Rasch Rating Scale Modeling of Data from the Standardized Letter of Recommendation. ETS Research Report Series, 2006(2), i-22. https:// doi.org/10.1002/j.23338504.2006.tb02038.x

Kjellström, S., Golino, H., Hamer, R., van Rossum, E. J., \& Almers, E. (2016). Psychometric properties of the Epistemological Development in Teaching Learning Questionnaire (EDTLQ): An inventory to measure higher order epistemological development. Frontline Learning Research, 4(5), 1-33. https:// doi.org/10.14786/ flr.v4i5.239

Kook, S. H., \& Varni, J. W. (2008). Validation of the Korean version of the pediatric quality of life inventory ${ }^{\mathrm{TM}} 4.0$ (PedsQL ${ }^{\mathrm{TM}}$ ) generic core scales in school children and adolescents using the rasch model. Health and Quality of Life Outcomes, 6, 41. https:/ / doi.org/10.1186/1477-7525-6-41

Kouadio, I. K., Aljunid, S., Kamigaki, T., Hammad, K., \& Oshitani, H. (2012). Infectious diseases following natural disasters: Prevention and control measures. Expert Review of Anti-Infective Therapy, 10(1), 95-104. https://doi.org/10.1586/eri.11.155

Kraemer, M. U. G., Yang, C.-H., Gutierrez, B., Wu, C.-H., Klein, B., Pigott, D. M., Groupt, O. C.-19 D. W., du Plessis, L., Faria, N. R., Li, R., Hanage, W. P., Brownstein, J. S., Layan, M., Vespignani, A., Tian, H., Dye, C., Pybus, O. G., \& Scarpino, S. V. (2020). The effect of human mobility and control measures on the COVID-19 epidemic in China. Science, 368(6490), 493-497. https://doi.org/10.1126/ science.abb4218

Lewandowsky, S., Mann, M. E., Brown, N. J. L., \& Friedman, H. (2016). Science and the public: Debate, denial, and skepticism. Journal of Social and 
Political Psychology, 4(2), 537-553. https:/ / doi.org/10.5964/jspp.v4i2.604

Linacre, J. (1994). Sample Size and Item Calibration Stability. Rasch Measurement Transactions, 7, 328.

Linacre, J. M. (1998). Detecting multidimensionality: Which residual data-type works best? Journal of Outcome Measurement, 2(3), 266-283.

Lipovetsky, S. (2020). Modern Psychometrics With R. Technometrics, 62(1), 135-137. https://doi.org/ 10.1080/00401706.2019.1708675

Malm, H., May, T., Francis, L. P., Omer, S. B., Salmon, D. A., \& Hood, R. (2008). Ethics, pandemics, and the duty to treat. American Journal of Bioethics, 8(8), 4-19. https:/ / doi.org/10.1080/15265160802317974

McDonald, R. P., \& Ho, M.-H. R. (2002). Principles and practice in reporting structural equation analyses. Psychological Methods, 7(1), 64-82. https:/ / doi.org/ 10.1037/1082-989x.7.1.64

Mohd Hanafiah, K., \& Wan, C. Da. (2020). Public knowledge, perception and communication behavior surrounding COVID-19 in Malaysia. https://doi.org/10.31124/advance.12102816.v1

Müller, S., Kohlmann, T., \& Wilke, T. (2015). Validation of the Adherence Barriers Questionnaire - an instrument for identifying potential risk factors associated with medication-related non-adherence. BMC Health Services Research, 15(1), 153. https:/ / doi.org/10.1186/s12913-015-0809-0

Olapegba, P. O., \& Ayandele, O. (2020). Survey data of COVID-19-related Knowledge, Risk Perceptions and Precautionary Behavior among Nigerians. Data in Brief, 105685. https://doi.org/10.1016/j.dib. 2020.105685

Rahman, A., \& Sathi, N. J. (2020). Knowledge, attitude, and preventive practices toward COVID-19 among Bangladeshi internet users. Electronic Journal of General Medicine, 17(5), em245. https://doi.org/ 10.29333 / ejgm/ 8223

Rodrigues, I. B., Adachi, J. D., Beattie, K. A., \& MacDermid, J. C. (2017). Development and validation of a new tool to measure the facilitators, barriers and preferences to exercise in people with osteoporosis. BMC Musculoskeletal Disorders, 18. https:/ / doi.org/10.1186/s12891-017-1914-5

Saefi, M., Fauzi, A., Kristiana, E., Adi, W. C., Muchson, M., Setiawan, M. E., Islami, N. N., Ningrum, D. E. A. F., Ikhsan, M. A., \& Ramadhani, M. (2020). Survey data of COVID-19-related knowledge, attitude, and practices among Indonesian undergraduate students. Data in Brief, 31, 105855. https://doi.org/10.1016/j.dib.2020.105855

Sahu, P. (2020). Closure of Universities Due to Coronavirus Disease 2019 (COVID-19): Impact on Education and Mental Health of Students and
Academic Staff. Cureus, 12. https://doi.org/ 10.7759 / cureus.7541

Saravara, S. I. I. I. J. (2007). Business continuity planning in higher education due to pandemic outbreaks business continuity planning in higher education due to pandemic outbreaks: A faculty perspective. Journal of Security Education, 2(3), 41-51. https:/ / doi.org/10.1300/J460v02n03

Singhal, T. (2020). A review of Coronavirus Disease-2019 (COVID-19). The Indian Journal of Pediatrics, 87. https:/ / doi.org/10.1007/s12098-020-03263-6

Sirkeci, I., \& Yüceşahin, M. (2020). Coronavirus and Migration: Analysis of Human Mobility and the Spread of COVID-19. Migration Letters, 17, 379-398. https://doi.org/10.33182/ml.v17i2.935

Smith, A. B., Rush, R., Fallowfield, L. J., Velikova, G., \& Sharpe, M. (2008). Rasch fit statistics and sample size considerations for polytomous data. BMC Medical Research Methodology, 8(1), 33. https:/ / doi.org/10.1186/1471-2288-8-33

Tabachnick, B. G., \& Fidell, L. S. (2007). Using Multivariate Statistics (5th ed). Pearson/Allyn \& Bacon.

Takahashi, S., Sato, K., Kusaka, Y., \& Hagihara, A. (2017). Public preventive awareness and preventive behaviors during a major influenza epidemic in Fukui, Japan. Journal of Infection and Public Health, 10(5), 637-643. https:/ / doi.org/10.1016/j.jiph.2017. 04.002

Taylor, D. L., Kahawita, T. M., Cairncross, S., \& Ensink, J. H. J. (2015). The impact of water, sanitation and hygiene interventions to control cholera: A systematic review. PLoS ONE, 10(8), 1-19. https:// doi.org/10.1371/journal.pone.0135676

Tennant, A., \& Conaghan, P. G. (2007). The Rasch measurement model in rheumatology: What is it and why use it? When should it be applied, and what should one look for in a Rasch paper? Arthritis $\mathcal{E}$ Rheumatism, 57(8), 1358-1362. https://doi.org/ 10.1002/art.23108

Uscinski, J. E., Enders, A. M., Klofstad, C., Seelig, M., Funchion, J., Everett, C., Wuchty, S., Premaratne, K., \& Murthi, M. (2020). Why do people believe COVID-19 conspiracy theories? Harvard Kennedy School Misinformation Review. https://doi.org/ 10.37016/mr-2020-015

Wadood, Md. A., Mamun, A., Rafi, Md. A., Islam, kamrul Md., Mohd, S., Lee Lee, L., \& Hossain, Md. G. (2020). Knowledge, attitude, practice and perception regarding COVID-19 among students in Bangladesh: Survey in Rajshahi University. https://doi.org/ 10.1101/2020.04.21.20074757

Wang, C., Cheng, Z., Yue, X.-G., \& McAleer, M. (2020). Risk Management of COVID-19 by Universities in 
China. Journal of Risk and Financial Management, 13(2), 36. https:/ / doi.org/10.3390/jrfm13020036

Zhong, B.-L., Luo, W., Li, H.-M., Zhang, Q.-Q., Liu, X.G., Li, W.-T., \& Li, Y. (2020). Knowledge, attitudes, and practices towards COVID-19 among Chinese residents during the rapid rise period of the COVID-19 outbreak: A quick online cross-sectional survey. International Journal of Biological Sciences, 16(10), 1745-1752. https://doi.org/10.7150/ ijbs. 45221

\section{http://www.ejmste.com}

